\title{
Effect of Natural Gas Composition on the Performance of a CNG Engine
}

\author{
K. Kim ${ }^{1}$, H. Kim ${ }^{1}$, B. Kim², K. Lee ${ }^{1 *}$ and K. Lee ${ }^{3}$ \\ 1 Department of Mechanical Engineering, Hanyang University, 1271 Sa 1-dong, Sangnok-gu, Ansan-si, Gyeonggi-do, $426-791$ - Republic of Korea \\ 2 Korea Gas Corporation, 638-1 II-dong, Ansan-si, Gyeonggi-do - Republic of Korea \\ 3 Department of Mechanical Engineering, Hanyang University, 17 Hangdang-dong, Sungdonggu, Seoul, $133-070$ - Republic of Korea \\ e-mail: kimkb1 $1 @$ hanyang.ac.kr - hyung2k@hanmail.net - bongbong@kogas.or.kr - hylee@hanyang.ac.kr -ksleehy@hanyang.ac.kr \\ * Corresponding author
}

\begin{abstract}
Résumé - Effet de la composition du gaz naturel sur les performances d'un moteur GNC Le Gaz Naturel Comprimé (GNC) est considéré comme un carburant pour véhicule alternatif en raison de ses avantages économiques et environnementaux. Cependant, il est prouvé que la composition variable des gaz naturels produits dans diverses régions du monde affecte les performances et les taux d'émissions des moteurs GNC. Ainsi, l'objectif de cet essai est de corroborer l'effet de la composition du carburant sur la combustion et sur le taux d'émissions des moteurs GNC. Cet essai présente les caractéristiques de combustion globales obtenues en faisant fonctionner un moteur GNC de 2,5 L de quatre cylindres, posé en deuxième monte sur la base d'un moteur diesel à injection directe et équipé d'un dynamomètre. La puissance du moteur, la consommation de carburant spécifique au freinage, la pression de combustion et les émissions ont été mesurées dans des conditions de fonctionnement constantes en pleine charge et en charge partielle. Les résultats de l'expérience ont montré que la composition du GNC a un impact considérable sur les performances du moteur, sur la consommation de carburant et sur la vitesse de combustion. Une corrélation a été suggérée pour mieux comprendre la relation qui existe entre l'indice de Wobbe (IW) et la puissance du moteur. Elle propose une méthode pratique pour estimer la puissance du moteur lorsque la composition des gaz naturels varie.
\end{abstract}

\footnotetext{
Abstract - Effect of Natural Gas Composition on the Performance of a CNG Engine - Compressed Natural Gas (CNG) is considered an alternative vehicle fuel because of its economical and environmental advantages. However, the varying composition of natural gases produced in different parts of the world is known to affect the performance and emissions of CNG engines. Thus, the objective of this paper is to corroborate the effect of fuel composition on the combustion and emissions of CNG engines. This paper presents the overall combustion characteristics obtained from running a $2.5 \mathrm{~L}, 4-$ cylinder CNG engine, retrofitted from an IDI diesel engine and equipped with an engine dynamometer. Engine power, BSFC, combustion pressure, and emissions were measured under steady state operation conditions at full and partial loads. Experimental results showed that the CNG composition had a significant influence on engine performance, fuel economy, and burning rate. A correlation has been proposed to help gain insight into the relationship between the Wobbe Index (WI) and engine power, and it provides a practical method for estimating the engine power when the composition of natural gases changes.
} 


\section{INTRODUCTION}

In recent years, the development of alternative fuels has drawn much attention due to a shortage of crude oil and the enhancement of environmental regulations. Compressed Natural Gas (CNG) is considered a reliable alternative fuel that can satisfy new requirements, namely a reduction in air pollution and a stable energy supply [1]. CNG has many other advantages as well. It has a high octane number of 130 , which enables an engine to operate with little knocking at a high compression ratio. In addition, gasoline and diesel engines can be easily converted into $\mathrm{CNG}$ engines without major structural changes [2]. Not only does the $\mathrm{CNG}$ engine have good thermal efficiency and high power, but its combustion range is also broad. This is an advantage when striving for lean combustion resulting in low fuel consumption and less NOx production [3]. The CNG engine also yields very low levels of PM emissions when compared with other conventional engines. These facts are supported by an experimental study performed to explore the combustion and emissions characteristics of both gasoline and CNG fuels using a converted spark ignition engine [4]. In light of these advantages, the number of CNG vehicles is continuously growing, and old vehicles are being converted into CNG vehicles through engine modifications [5].

In addition, large underground resources, a countless number of production areas, and a competitive price make supplies of natural gas stable and reliable. However, the composition of natural gas is very diverse and is highly dependent on the production area, season, and climate. It is well known that such diversity in fuel composition affects engine performance and emission characteristics. In a study involving eight different kinds of natural gases, a research group revealed that the air to fuel ratio changes with different fuel composition, and the change in ratio was proportional to the Wobbe Index (WI) [6]. A similar result was obtained by another group that observed a power variation of up to $20 \%$ and a change in emission characteristics with diverse fuel composition [7]. Kubesh et al. (1992) emphasized that a change in octane number resulting from a change in fuel composition had a critical influence on vehicle driving conditions near knock-limited power, and they developed a correlation between the octane number and gas composition [2]. In contrast, a study performed with two extremely different compositions chosen among twelve CNGs in Texas found that the CNG composition had a negligible impact on emission characteristics [8].

Currently, natural gas is imported from only a few countries in Korea due to low demand. However, when the consumption of the gas goes up, gases having various fuel compositions will be imported from diverse production areas. Eventually, the various compositions of gas will affect the power and emission characteristics of vehicles. Therefore, the objective of this study is to understand the combustion and emission characteristics of gases in $\mathrm{CNG}$ engines, and to establish a correlation that can provide a practical method for determining the power output of $\mathrm{CNG}$ engines operating with various natural gases.

\section{EXPERIMENTAL APPARATUS AND METHOD}

\subsection{Experimental Setup}

In this study, a 2476 cc 4 cycle indirect injection (IDI) diesel engine was converted into the $\mathrm{CNG}$ engine as shown in Figure 1. The specifications of the engine are summarized in Table 1. An injector on the diesel head was taken off and replaced with a spark plug. A CNG injector (Bosch) was installed at the intake port for fuel injection. An oxygen sensor was installed at the exhaust port, which enables fuels injected into the combustion chamber to be controlled in a

TABLE 1

\begin{tabular}{|c|c|c|c|c|}
\hline \multicolumn{5}{|c|}{ Specifications of the CNG engine } \\
\hline & \multicolumn{2}{|c|}{ IDI diesel } & \multicolumn{2}{|c|}{$\mathrm{CNG}$} \\
\hline Cylinder & \multicolumn{2}{|c|}{4} & \multicolumn{2}{|c|}{4} \\
\hline $\begin{array}{l}\text { Displacement } \\
\text { volume }\end{array}$ & \multicolumn{2}{|c|}{$2476 \mathrm{cc}$} & \multicolumn{2}{|c|}{$2476 \mathrm{cc}$} \\
\hline Bore & \multicolumn{2}{|c|}{$91.5 \mathrm{~mm}$} & \multicolumn{2}{|c|}{$91.5 \mathrm{~mm}$} \\
\hline Stroke & \multicolumn{2}{|c|}{$95 \mathrm{~mm}$} & \multicolumn{2}{|c|}{$95 \mathrm{~mm}$} \\
\hline \multirow{2}{*}{ Valving timing } & IVO & BTDC $20^{\circ}$ & EVO & $\mathrm{BBDC} 20^{\circ}$ \\
\hline & IVC & $\mathrm{ABDC} 20^{\circ}$ & EVC & ATDC $20^{\circ}$ \\
\hline Compression ratio & \multicolumn{2}{|c|}{21.5} & \multicolumn{2}{|c|}{12.5} \\
\hline Injection type & \multicolumn{2}{|c|}{ In-direct injection } & \multicolumn{2}{|c|}{ Port fuel injection } \\
\hline
\end{tabular}

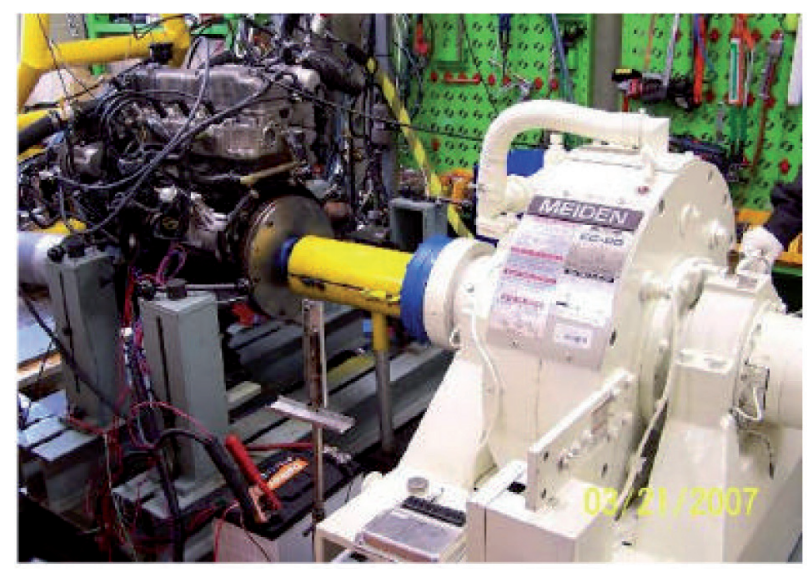

Figure 1

Photograph of the CNG engine and dynamometer system. 


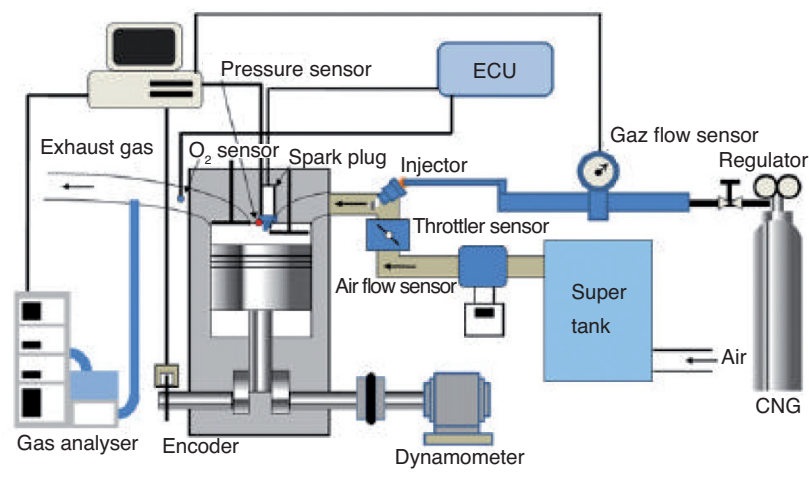

Figure 2

Schematic diagram of the experimental apparatus.

stoichiometric air to fuel ratio with an Electronic Control Unit (ECU). Figure 2 shows a schematic of the experimental setup employed in this study. The flow rate of fuel was measured with an installed mass fuel flow meter (Micro motion CFM010), and pressure inside the combustion chamber was measured at the first combustion chamber using a spark plugtype pressure sensor (Kistler 6015B). In addition, an EC dynamometer (Meidensha-EC80, $220 \mathrm{~kW}$ ) was employed to measure torque and power, and exhaust analysis was carried out with an exhaust analyzer (Horiba-Mexa 7100D).

\subsection{Selection of Test Fuels}

Six different kinds of gases having various fuel compositions were selected to investigate the combustion and emission characteristics of gases: Ref. gas (commonly used in the Republic of Korea), four well-known natural gases, and a pure methane gas. Hereafter, the test gases are referred to as Gases A, B, C, D, E, and F in this paper. The compositions and properties of the test gases were tabulated in Table 2 . The properties for each gas were provided by the Korea Gas Corporation. Values for WI and the combustion potential (CP) were calculated using Equations (1) and (2), where WI is an index determined by the low heating value of gas, and the $\mathrm{CP}$ is a value that can provide the theoretical burning velocity of a mixed gas based on the burning velocity of hydrogen.

$$
\begin{gathered}
\mathrm{WI}=\frac{\mathrm{LHV}}{\sqrt{\mathrm{SG}}} \\
\mathrm{CP}=k \frac{\mathrm{H}_{2}+0.6\left(\mathrm{CO}+\mathrm{C}_{\mathrm{m}} \mathrm{H}_{\mathrm{n}}\right)+0.3 \mathrm{CH}_{4}}{\sqrt{\mathrm{SG}}}
\end{gathered}
$$

$k$ : correction factor adjusted by the $\mathrm{O}_{2}$ concentration in the fuel.
TABLE 2

Compositions and properties of test fuels

\begin{tabular}{c|r|r|r|r|r|r}
\hline & $($ Gas A) & $\begin{array}{r}\text { Ref. gas } \\
(\text { Gas B })\end{array}$ & $\begin{array}{r}\text { Tangguh } \\
(\text { Gas C) }\end{array}$ & $($ Gas D) & (Gas E) & $\begin{array}{r}\text { Methane } \\
\text { (Gas F })\end{array}$ \\
\hline $\mathrm{CH}_{4}$ & 87.6 & 90.09 & 91.64 & 93.49 & 96.96 & 100 \\
\hline $\mathrm{C}_{2} \mathrm{H}_{6}$ & 8.4 & 6.04 & 1.93 & 5.08 & 2.6 & 0 \\
\hline $\mathrm{C}_{\mathrm{g}} \mathrm{H}_{\mathrm{g}}$ & 3.48 & 2.54 & 5.65 & 1.16 & 0.3 & 0 \\
\hline $\mathrm{IC}_{4} \mathrm{H}_{10}$ & 0.42 & 0.54 & 0.16 & 0.08 & 0.07 & 0 \\
\hline $\mathrm{NC}_{4} \mathrm{H}_{10}$ & 0.54 & 0.58 & 0.1 & 0.11 & 0.05 & 0 \\
\hline $\mathrm{IC}_{5} \mathrm{H}_{12}$ & 0.02 & 0.02 & 0 & 0.01 & 0.01 & 0 \\
\hline $\mathrm{NC}_{5} \mathrm{H}_{12}$ & 0.01 & 0 & 0 & 0.01 & 0 & 0 \\
\hline $\mathrm{N}_{2}$ & 0.07 & 0.19 & 0.42 & 0.06 & 0.01 & 0 \\
\hline Propylene & - & - & 0.1 & - & - & - \\
\hline $\mathrm{Total}$ & 100 & 100 & 100 & 100 & 100 & 100 \\
\hline $\mathrm{HHV}$ & 10835.3 & 10549.8 & 10500.8 & 10096.4 & 9781.3 & 9523.4 \\
\hline $\mathrm{LHV}$ & 9798.5 & 9532.3 & 9487.3 & 9109 & 8814.8 & 8574.1 \\
\hline $\mathrm{SG}$ & 0.645 & 0.627 & 0.626 & 0.594 & 0.573 & 0.555 \\
\hline $\mathrm{WI}$ & 12201 & 12040 & 11991 & 11814 & 11650 & 11510 \\
\hline $\mathrm{CP}$ & 42.1 & 41.5 & 40.7 & 41.4 & 40.8 & 40.3 \\
\hline $\mathrm{MON}$ & 118.8 & 121.9 & 122.1 & 125.3 & 134.3 & 140 \\
\hline $\mathrm{MN}$ & 68.3 & 72.7 & 73.1 & 77.7 & 90.7 & 100 \\
\hline Density & 0.834 & 0.81 & 0.809 & 0.769 & 0.74 & 0.717 \\
\hline & & & & & & \\
\hline
\end{tabular}

In Equations (1) and (2), LHV and SG denote the lower heating value and specific gravity of the gas, respectively.

\subsection{Experimental Conditions and Methods}

The effect of gas composition on combustion and emission characteristics can be explained in terms of the WI. This effect was investigated at the Wide Open Throttle (WOT) and the partial load conditions. Spark timing was controlled based on the MBT (Maximum Brake Torque) of Ref. gas. The experimental conditions are listed in Table 3. In the partial load regime, the throttle opening was fixed at $1 / 3$ and gases and engine speed were varied to explore how combustion and emissions were affected by the change in fuel composition. The maximum torque and power of the engine were measured at two load conditions. The Brake Specific Fuel Consumption (BSFC) was calculated using both the engine power measured with a dynamometer and the fuel flow rate measured with a mass fuel flow meter. The Rate Of Heat Release (ROHR) and the Mass Burn Fraction (MBF) were also determined using pressure measured in the combustion chamber with a pressure sensor. Concentrations of THC and NOx were measured with an exhaust analyzer and normalized by the engine power. 
TABLE 3

\begin{tabular}{c|c}
\multicolumn{2}{c}{ Specifications of the CNG engine } \\
\hline & Conditions \\
\hline Engine speed & $1000 \sim 4000$ RPM \\
\hline Fuels & Ref. gas 외 5 쫑 \\
\hline Load & WOT. Partial load \\
\hline Spark timing & Fixed (MBT of Ref. gas) \\
\hline Intake condition & N.A. \\
\hline Excess air ratio & $0.8 \mathrm{MPa}$ \\
\hline Injection pressure &
\end{tabular}

\subsection{Simulation Model}

In order to validate the experimental results, a simulation study was performed using software (i.e. Wave code) that is a one-dimensional engine analyzing tool. The one dimensional CNG engine simulation model is represented in Figure 3. The SI Wiebe model was employed for combustion, and a basic Woschni model was used for heat transfer of the CNG engine. Both an intake flow coefficient and a swirl ratio affecting the engine performance were determined for the simulation based on a steady flow experiment.

\section{EXPERIMENTAL RESULTS AND DISCUSSION}

\subsection{Power Performance of the CNG engine}

The power performance of the converted $\mathrm{CNG}$ engine was evaluated under the WOT condition. Figure 4 shows the power and torque as a function of the engine speed (RPM) and fuel composition. The maximum torque for all gases was observed at an engine speed of 2200 RPM. Gas A showed a maximum torque of $150 \mathrm{Nm}$. It should also be noted that the torque data at both high and low RPM values varied significantly with gas composition. Likewise, the maximum power was observed at an engine speed of 3400 RPM. Gas A yielded the maximum observed power of $48 \mathrm{~kW}$.

Figure 5 illustrates the relative power to Gas B with respect to the fuel composition and the engine speed. The data indicate that from 1000 to 4000 RPM, all of the gases yield less power than Gas B with the exception of Gas A. The difference in the power of the gases is especially noticeable at the low and high engine speed regions. When Gas E was used, the power dropped approximately $9 \%$ at the extreme RPM values. It was observed that the engine power appears to be proportional to the WI value of the gas used. The engine performance at the WOT condition was severely affected by the variation in heating values resulting from differing fuel composition. Consequently, the effect of the fuel composition on the change in engine power could be estimated using the WI value of the gas.

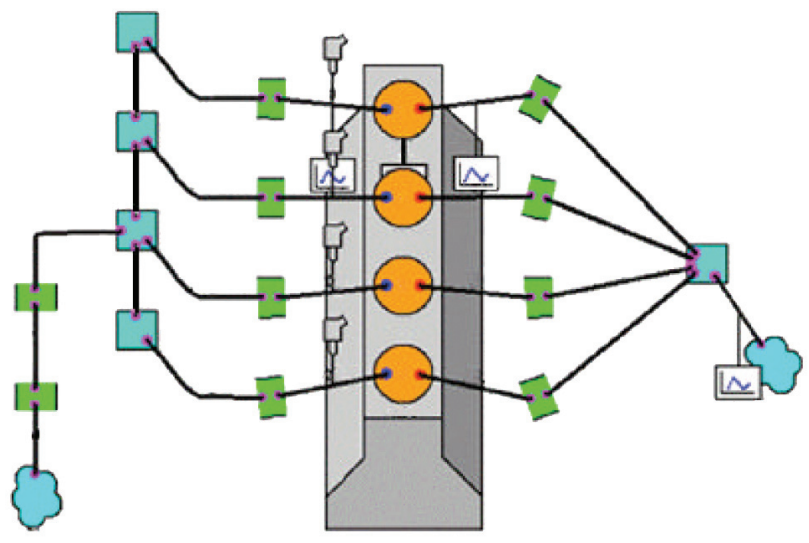

Figure 3

Simulation model for $\mathrm{CNG}$ engine modeling.

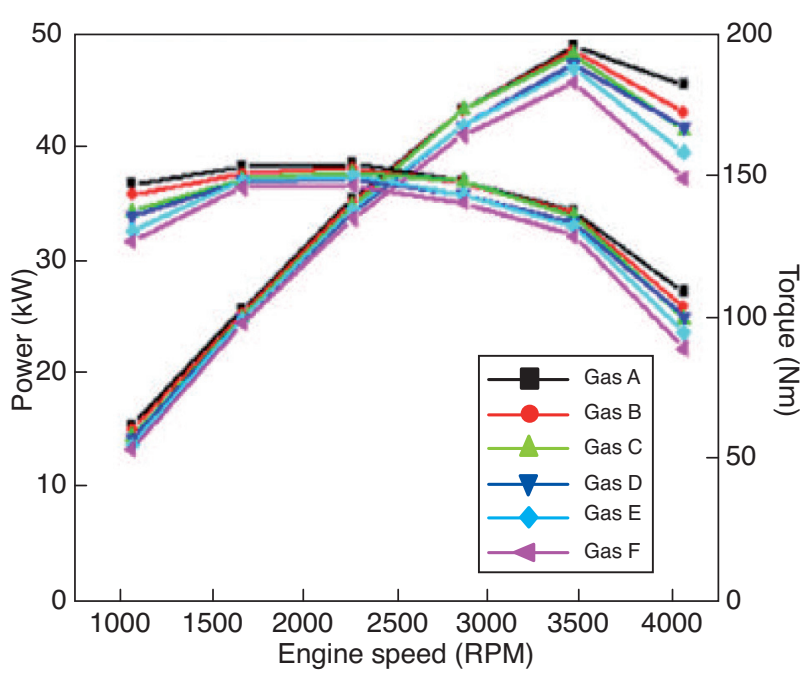

Figure 4

Effect of gas composition on the CNG engine power and torque characteristics at WOT condition.

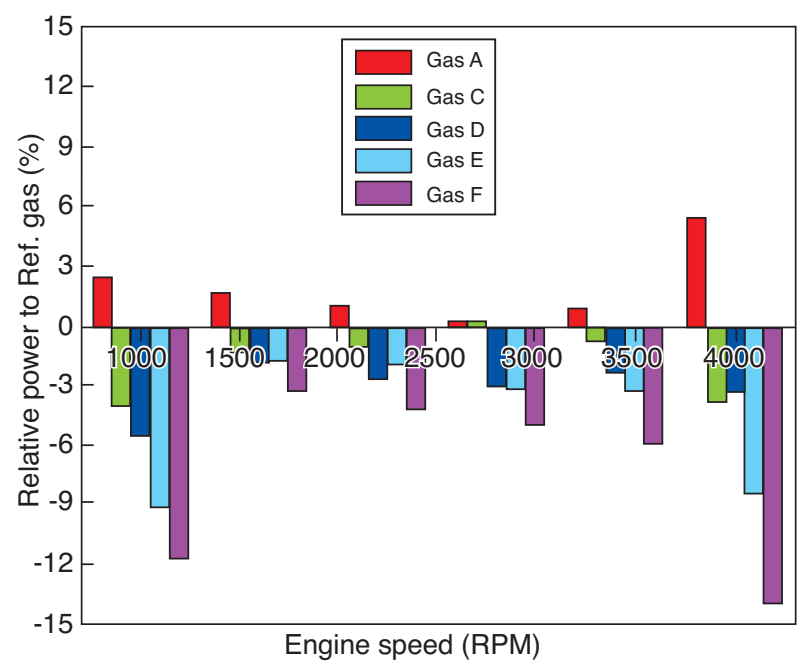

Figure 5

Relative engine power output normalized by Ref. gas data. 


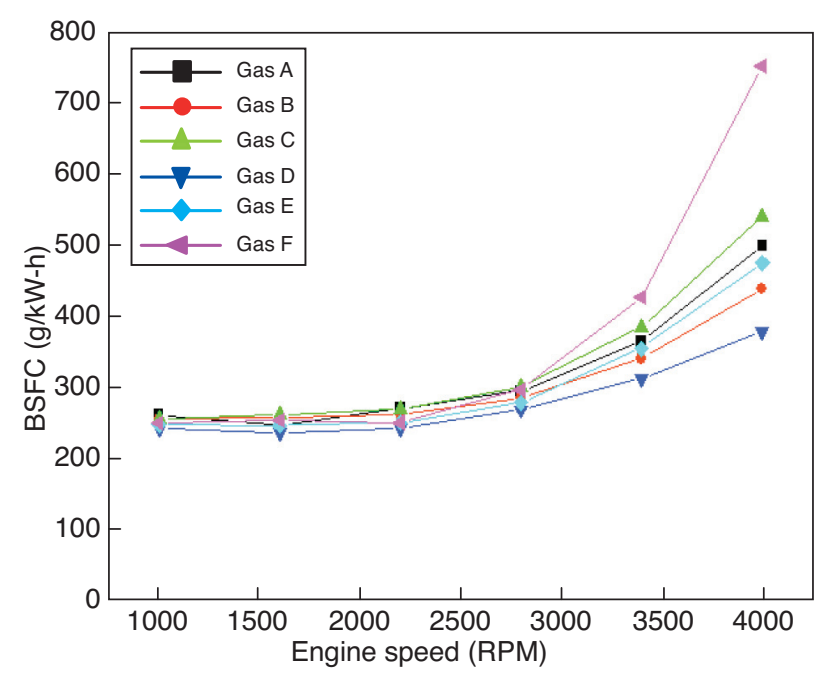

Figure 6

Effect of fuel composition and engine speed on the BSFC at partial load.

\subsection{Characteristics of Fuel Consumption}

The effect of fuel composition and engine speed on the BSFC at partial load is described in Figure 6. The BSFC increases for all of the gases as the engine speed increases. Figure 6 shows that Gas D has the best BSFC. Additionally, the BSFC of Gas F rises rapidly when the engine operates between 3400 and 4000 RPM. The BSFC is expected to be inversely proportional to the WI values of the gas. Thus, a low BSFC is expected for fuels having higher WI values. However, our results were not consistent with this expectation. A reasonable explanation for this behavior can be made using $\mathrm{CP}$ values and the amount of nitrogen contained in the gases.

According to a study by Min et al. (2002), the Maximum Brake Torque (MBT) increases with decreasing CP that has an effect on the spark timing of an engine. The spark timing of the engine for a gas with a small CP needs to be set early, so that the initial flame has sufficient time to fully develop. However, the spark timing of the engine used in the present study was set for Gas B at MBT. As noted in Table 2, Gases F, C, and E have smaller CP values than does Gas B. These gases were considered to have consumed more fuel in order to achieve the same power production.

In addition to the $\mathrm{CP}$ value, the quantity of nitrogen in gases plays a crucial role in the determination of the spark timing, because nitrogen slows down flame propagation. Gas D not only has a very similar CP compared to that of Gas B, but it also contains a smaller amount of nitrogen in comparison to Gas B. This could be one reason why the best BSFC was obtained with Gas D in this experiment. The overall deviation of the BSFC for all of the fuels is less than $10 \%$ when the engine speed is below 2800 RPM. However, the deviation is more than $20 \%$ when the engine speed is over 2800 RPM. Therefore, a change in fuel composition will require frequent adjustment of the spark timing of the engine to keep it operating at the same power. Failure to make this adjustment will lead to a change in the fuel consumption.

\subsection{Combustion Characteristics}

In order to investigate the effect of fuel composition on combustion, in-cylinder pressures were measured at an engine speed of 2200 RPM and then plotted with respect to the crank angle. The results are shown in Figures 7 and 8. The in-cylinder pressure was proportional to the WI at the WOT condition, which follows the same trend that was observed in the power performance test. An increase in the cylinder pressure resulting from the higher rate at which heat is being released is responsible for increasing the engine power. In the same manner, the pressure was measured at the partial load condition, and the result was consistent with the BSFC result. The highest in-cylinder pressure was observed with Gas D, and the lowest pressure was recorded with Gas F.

The MBF at partial load was calculated with the ROHR and plotted as a function of crank angle in Figure 9. The MBF of Gas B starts increasing early at the lower crank angle, while the MBF of Gas F lags slightly behind. The fact that the spark timing is fixed for Gas B may affect the MBF result of Gas F.

It was found that various fuel compositions seemed to have a greater influence on combustion characteristics at partial load than they did at the WOT condition. Furthermore, it appears that there are many factors affecting the engine combustion characteristics, including the WI value. One of the

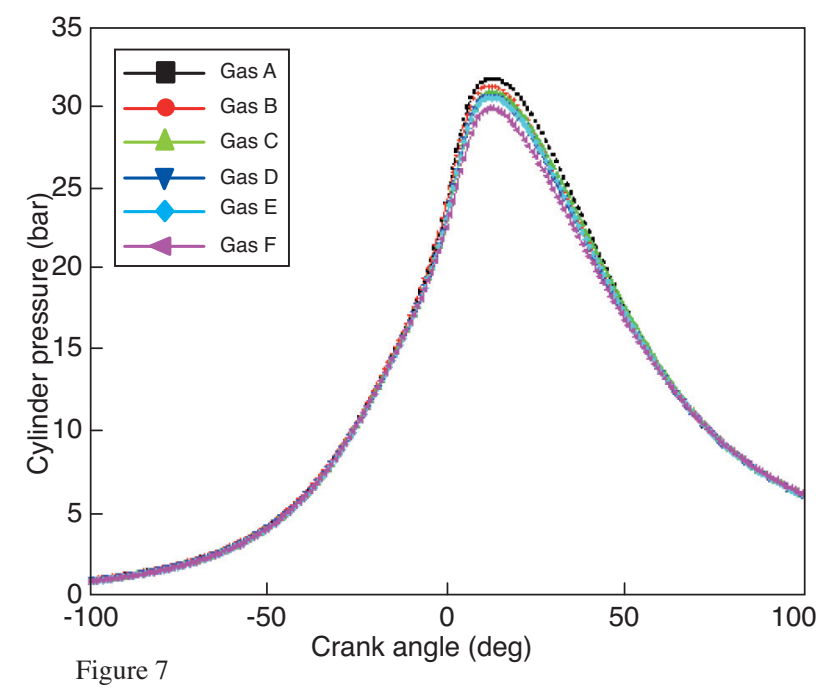

In-cylinder pressure at WOT as a function of crank angle and gas composition. The pressure was measured at an engine speed of 2200 RPM. 


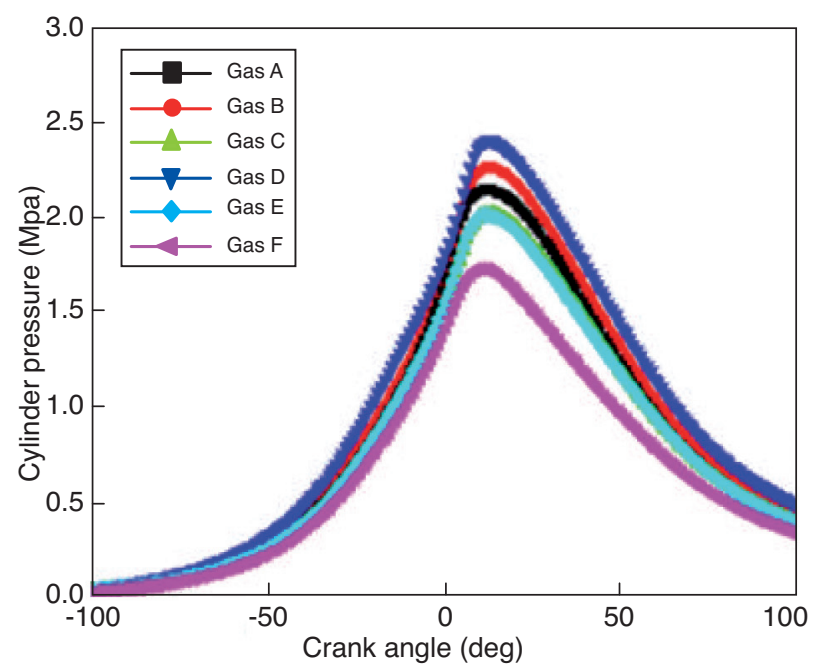

Figure 8

In-cylinder pressure at partial load as a function of crank angle and gas composition. The pressure was measured at an engine speed of 2200 RPM.

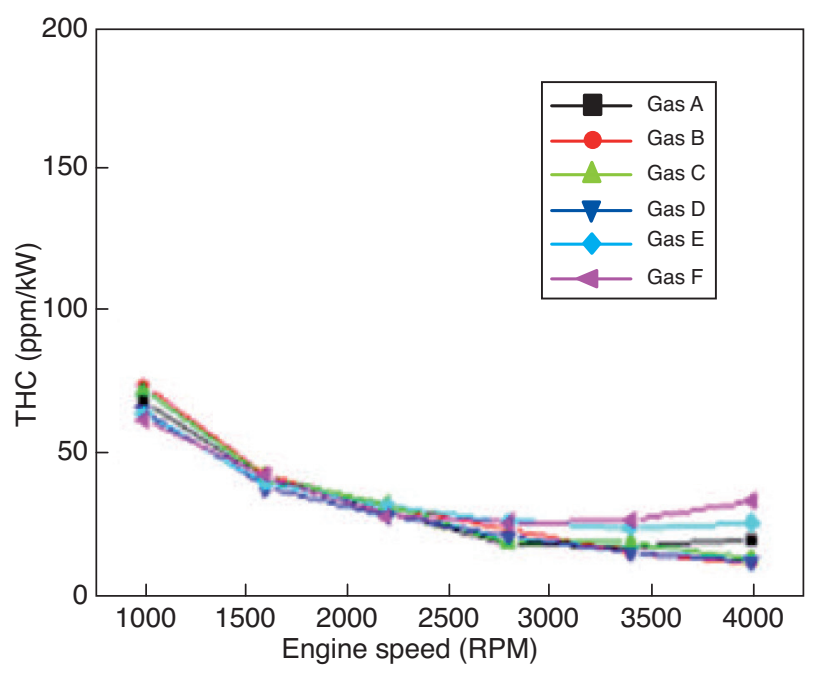

Figure 10

Effect of fuel composition and engine speed on THC emissions at partial load.

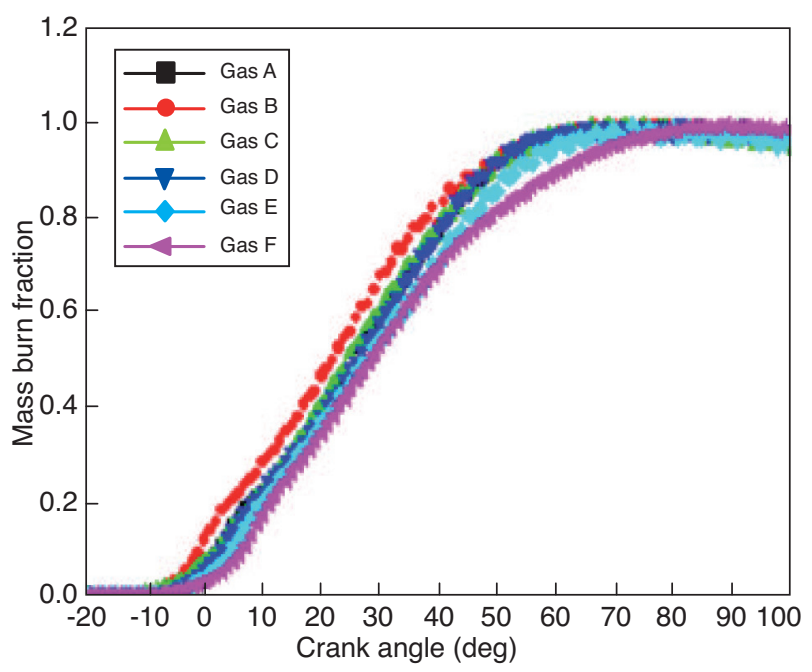

Figure 9

Mass burn fraction at partial load as a function of crank angle.

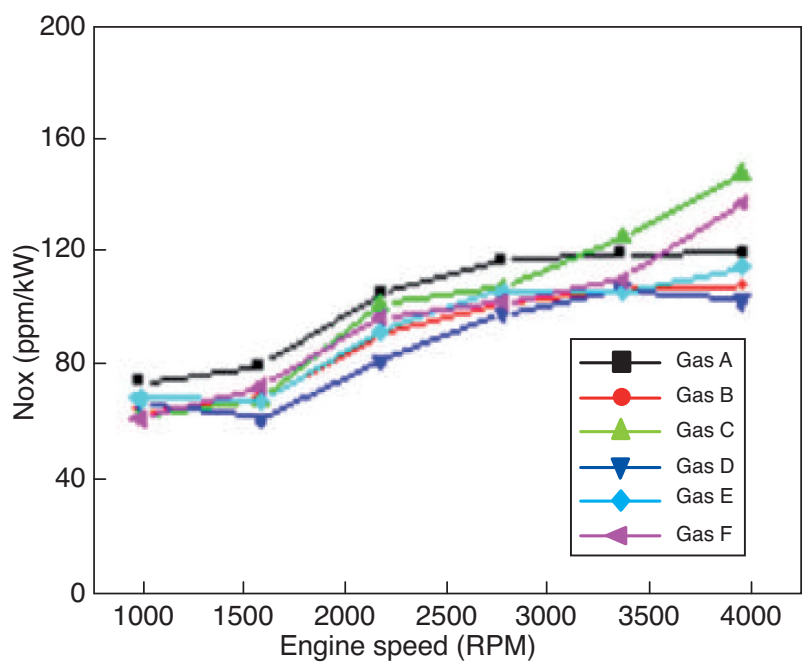

Figure 11

Effect of fuel composition and engine speed on Nox emissions at partial load. most significant factors that helps determine the combustion characteristics is the spark timing. Another factor that affects engine performance is the burning velocity for fuels of different compositions. The burning velocities of these fuels will be measured in a future study using a constant volume combustion chamber.

\subsection{Emission Characteristics}

Figure 10 shows the effect of fuel composition and engine speed on THC emission at a partial load. As the engine speed increases, all fuels emit less THC because combustion becomes activated. With regard to the relationship between THC emissions and WI, THC emissions increase with a decrease in WI. In the case of a gas with a lower WI, the engine needs more fuel to operate at the same engine speed. This fact is consistent with the results at higher engine speeds. However, in spite of a lower WI, Gases B and C yielded a lower amount of THC emissions at 4000 RPM than Gas A. This is because these two gases have more nitrogen than Gas A. On the other hand, no distinct trend of THC emission was observed at lower engine speeds. 


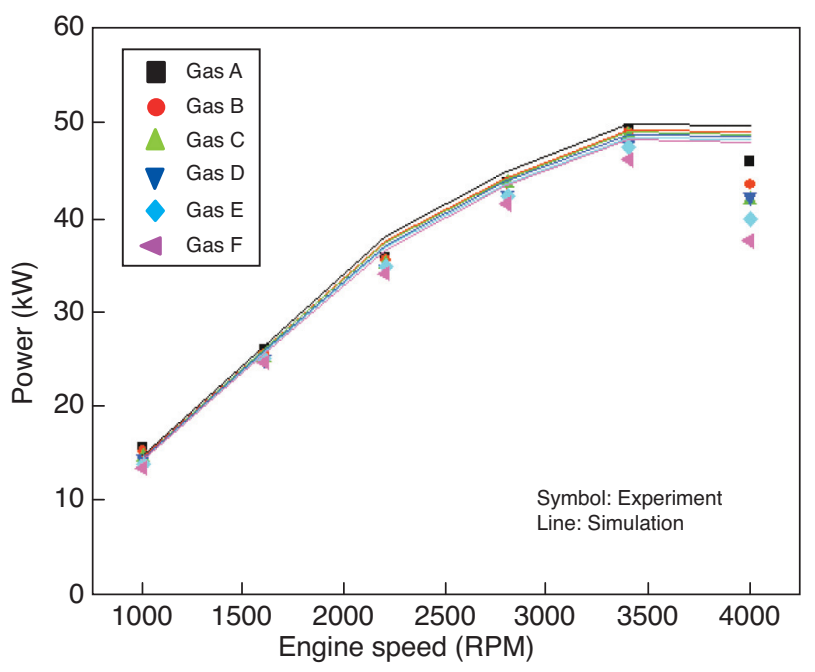

Figure 12

Comparison of engine power results between the simulation and the experiment.

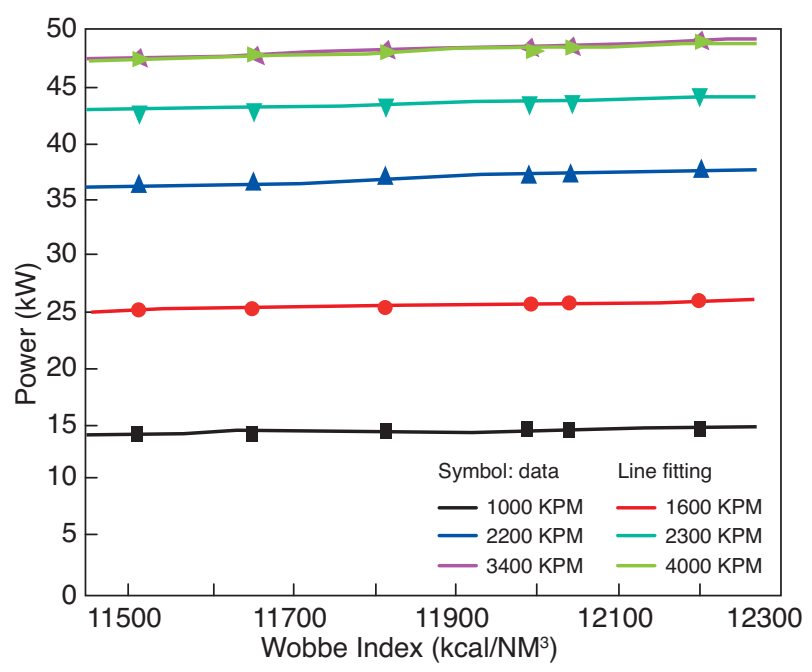

a)

\section{Figure 14}

Engine power as a function of the Wobbe index. a) Curve fitting result. b) Coefficients of correlation.

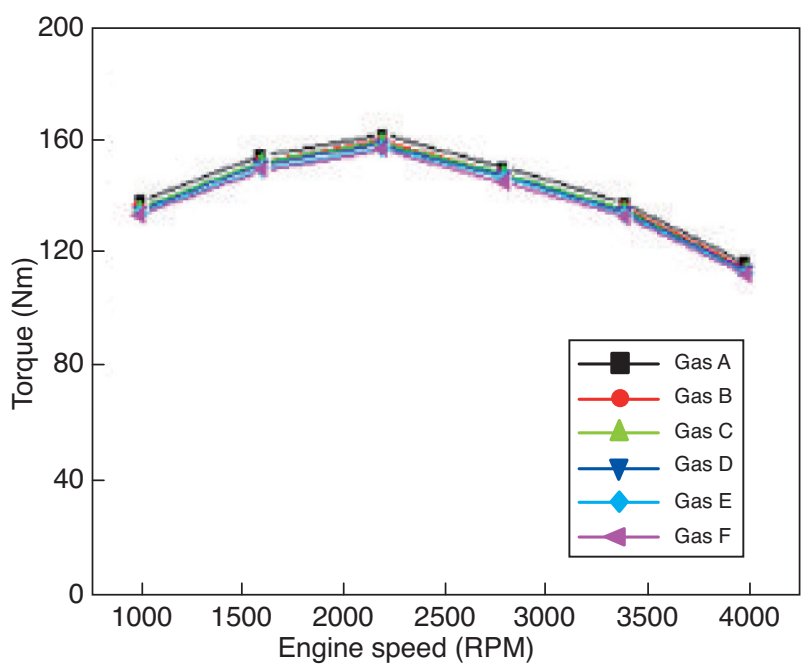

Figure 13

Comparison of torque results between the simulation and the experiment.

\begin{tabular}{|c|c|c|}
\hline Coefficient & A & B \\
\hline 1000 & $6.56 \mathrm{E}-04$ & 6.53544 \\
\hline 1500 & 0.00118 & 11.59453 \\
\hline 2200 & 0.00173 & 16.40692 \\
\hline 2800 & 0.00199 & 20.03344 \\
\hline 3400 & 0.00221 & 22.29012 \\
\hline 4000 & 0.0022 & 22.14636 \\
\hline & Y A x WI + B
\end{tabular}

b)
Y: Power (kW) WI: Wobbe Index
In the same manner, the effect of fuel composition and engine speed on NOx emissions at partial load was investigated. The results are shown in Figure 11. In general, the formation of NOx takes place during combustion, especially combustion at high temperatures. As shown in Figure 11, NOx emission increases with increasing engine speed for all fuels due to the activation of combustion. The NOx emission rate can also be correlated with WI, since the gas temperature is related to the WI. Therefore, it is not surprising that Gas A yields the highest overall NOx emission, except at higher engine speeds. At an engine speed of 1000 RPM, NOx emis- sion was the highest with Gas A, which has the largest WI, and emission was lowest with Gas F, which has the lowest WI. The lowest overall NOx emission rate over the whole RPM range was observed with Gas D, which may be attributable to the relatively precise spark timing. At high engine speeds, higher NOx formation was found with Gases $\mathrm{C}$ and F. High amounts of nitrogen contained in Gas $\mathrm{C}$ may contribute to this result. In addition, for Gas F, the imprecise spark timing causes the fuel to be rich at high engine speeds, which may result in more NOx formation. 


\subsection{Simulation Results}

A simulation study was carried out to validate the experimental results. Figure 12 shows the comparison of simulated and experimental results with regard to the engine power at WOT. The experimental results are in excellent agreement with the simulation results. The overall deviation of the results of the experiment from the simulation is approximately 5.2\%. The large deviation, observed at 4000 RPM, may be attributed to a large amount of fuel being injected into the cylinder to prevent the engine from overheating.

Figure 13 shows the simulation result of the effects of fuel composition and engine speed on torque at WOT. The torque is proportional to the WI, and the deviation is around $4 \%$.

The engine power was plotted in Figure 14a with respect to the WI and the engine speed. Linear equations for each speed were extracted using linear regression with a least squares approach. Figure 14b shows the line fitting results and the coefficients with respect to the engine speeds and the WI values. When fuel composition is changed, this correlation could provide a beneficial method for estimating the engine power for an engine with a known speed and a gas with a known WI.

\section{CONCLUSIONS}

This study was designed to explore the effect of fuel composition on emissions and combustion at partial load in a $\mathrm{CNG}$ engine retrofitted from an IDI diesel engine. The principle conclusions can be summarized as follows:

- It was observed that there are many other factors (e.g. spark timing) beyond fuel composition that affect the combustion and emission characteristics of a $\mathrm{CNG}$ engine. If such factors could be controlled, the WI could be used to understand how those characteristics change depending on the change in fuel composition.

- The engine power varies with the WI value. The influence of other factors on the engine performance appears to be negligible at the WOT condition, since the engine power at WOT was directly proportional to the WI value. That is, high power output is obtained as the WI increases. A linear equation was proposed to predict the change in power as a function of WI.
- Gas D showed the best fuel efficiency performance at partial load. For all fuels, the BSFC relative to Gas B is within $10 \%$ below 2800 RPM, while it deviates more than $20 \%$ when over 2800 RPM, with the exception of Gas F.

- The in-cylinder pressure is proportional to the WI at the WOT condition. Gas D shows the highest combustion pressure, and the MBF of Gas B is the largest. This is attributed to the fact that the MBT in this experiment was fixed for Gas B.

- Emission characteristics at partial load are affected by the WI, fuel composition, spark timing, and burning velocity.

\section{ACKNOWLEDGEMENT}

This work was funded by the Korea Gas Corporation. The authors appreciate this support.

\section{REFERENCES}

1 David P. (1996) Northern Lights Bright Prospects for Natural Gas Vehicles in Canada, Natural Gas Fuel.

2 Kubesh J., King S.R., Liss W.E. (1992) Effect of Gas Composition on Octane Number of Natural Gas Fuels, SAE 9223591992.

3 Lee Y., Kim G. (1999) Effect of Gas Compositions on Fuel Economy and Exhaust Emissions of Natural Gas Vehicles, KSAE 7, 8, 123-131.

4 Aslam M.U., Masjuki H.H., Kalam M.A., Abdesselam H., Mahlia T.M.I., Amalina M.A. (2006) An Experimental Investigation of $\mathrm{CNG}$ as an Alternative Fuel for a Retrofitted Gasoline Vehicle, Fuel 85, 5-6, 717-724.

5 Ryu K., Kim B. (2006) Development of Conversion Technology of a Decrepit Diesel Vehicle to the Dedicated Natural Gas Vehicle, KSAE 14, 6, 73-81.

6 Sakai T. (1996) Effect of Natural Gas Composition on Engine Performance And Exhaust Emissions, Jidosya Kennkyu 18, 1, 23-26.

7 Min B.H., Chung J.T., Kim H.Y., Park S.S. (2002) Effects of Gas Composition on the Performance And Emissions of Compressed Natural Gas Engines, KSME 16, 2, 219-226.

8 Matthews R., Chiu J., Hilden D. (1996) CNG Composition in Texas and the Effects of Composition on Emissions, Fuel Economy, and Driver-Ability of NGV's, SAE 9620971996.

Final manuscript received in March 2008 Published online in November 2008 